\title{
Analysis of Market Access Agreements in Turkey
}

\author{
Guvenc Kockaya ${ }^{1}$, Okan Atalay ${ }^{2}$, Mustafa Kurnaz ${ }^{1}$, Selin Okcun ${ }^{1}$, Nazlı Sencan ${ }^{3}$, \\ Cigdem Gedik ${ }^{4}$, Mete Saylan ${ }^{4}$, Gulpembe Oguzhan ${ }^{5}$

\begin{abstract}
BACKGROUND: Reimbursement agencies are increasingly adopting innovative reimbursement approaches for new and expensive technologies. Social Security Institution (SSI), Turkey`s reimbursement agency, established the Alternative Reimbursement Commission (ARC) on February 10, 2016. This study aimed to understand the implementations of market access agreements in recent years in Turkey.

METHODS: Decisions of the Health Services Pricing Commission published in the official gazette, and information from the Turkey Pharmaceuticals and Medical Devices Agency, the Abroad Drug List, Health Implementation Communique published by SSI with additional lists, such as the Annex-4A List of Reimbursed Medicines and the Annex-4C Abroad Drug Price List, were used. The data was transferred to Windows Office Excel files, and a descriptive analysis was conducted and evaluated by two market access experts.

RESULTS: There were 57 drugs included in the coverage of reimbursement with alternative reimbursement since the application was started in Turkey. 35 of them were added to Annex-4A and 22 of them to Annex-4C. Furthermore, $45.6 \%$ of the drugs had an Anatomic Therapeutic Chemical Classification (ATC) code of 1-antineoplastic and immunomodulating agents, $28 \%$ were orphan drugs, 44 of them had a confidential discount rate, and financial-based agreement models were preferred for nearly all agreements.

CONCLUSIONS: Turkey has been implementing market access agreements since mid-2016. In the past 3 years, 57 drugs have been covered for reimbursement under the new implementation. Further analysis should be conducted to understand the decision-making process involved.
\end{abstract}

\section{Keywords}

Market access; Risk-sharing agreements; Reimbursement

\section{BACKGROUND}

Improvements are being made to meet the ever-increasing demands and expectations in health services. It has become the health policy of all states to provide these services in an equal, timely, quality, and effective manner to all [1]. The purpose of health policies is to ensure that the system is sustainable [2] and manageable [3].

The main factors are the increase in the general population, the elderly population, and in chronic diseases, the widening of health-insurance coverage, and the change in the profile of diseases which are leading to changes in the health sector [4]. According to perceived benefits, individuals, businesses, and the state face difficult decisions on the allocation of health resources against the high costs of some interventions. High-priced drugs place considerable pressure on government budgets [5]. In the Organization of Economic Co-operation and Development (OECD) countries, one out of every five dollars for health is spent on medicines [6]. Considering economic concerns, states determined which intervention provides the highest value while keeping health costs under control [7]

The duties of the state and politicians include ensuring that people live healthily and have access to drugs [8]. Access to drugs is a concern not only for governments but also for pharmaceutical companies [9]. Four basic factors of drug access include physically and easy ac-

Corresponding author Guvenc Kockaya guvenc@kockaya.net

Received: 24 December 2019 Accepted: 9 October 2020 Published: 22 October 2020 
cess of the drug to patients, the supply of the required drug to the market, the ability of patients to afford drug prices, and the proven effectiveness of the drug [10].

The rapid developments in the health sector have enabled more effective and successful treatments for several diseases; however, the high research and development (R\&D) costs of the technologies they contain make it difficult for the paying institution and the patient in need [11]. Regarding the introduction and use of new health technologies, health technology assessment (HTA) is a systematic, transparent, and meticulous scientific approach that evaluates the clinical, economic, organizational, social, legal, and ethical effects of present and new technologies, and it provides information to decision makers and clinicians [12].

\section{MARKET ACCESS}

The concept of market access was first developed by the World Trade Organization (WTO), and it includes the opening of markets to trade, increasing transparency in international trade, reciprocity, and a lack of discrimination [13]. Market access, including licensing, pricing, and reimbursement processes in general, is a set of processes that ensure that a product is quickly and sustainably accessed by all eligible patients in need of that product at an affordable price to ensure maximum reimbursement and minimum restriction in financing $[14,15]$. The introduction of the product into the market is defined as the opening of countries' markets to new services and products. The World Health Organization (WHO) emphasizes that access to health care is a human right. Therefore, access to medicine or a health product is a human right [16].

Market access agreements are a form of guarantee offered by the pharmaceutical company for new and costly products [17]. Market access agreements can be regarded as sharing risks foreseen for a drug in terms of cost-effectiveness and budgetary impact analysis [18] for both the manufacturer and the reimbursement agency under the provisions of the contract with the pharmaceutical company. With these agreements, both parties aim to eliminate uncertainty from their perspective [16]. Furthermore, risk-sharing agreements are crucial to eliminate the risk caused by exchange rate fluctuations between any two countries [19].

How long will market access have different meanings for the pharmaceutical company, clinicians, patient, and paying institutions? The more quickly the pharmaceutical company provides access to the market, the more successful and the more profitable it will be. Clinicians want the ability to prescribe different treatment options to the patient, and the patient wants to access new technologies as quickly as possible. The reimbursement institution has to consider total drug expenditures, its proportion in health expenditures, the balances in the market, and the sustainability factor while providing the patient with the drug he or she needs. To make a decision, the evidence must be sufficiently convincing and prompt. Furthermore, the uncertainties should be tolerated, and the value of the drug should be trusted.

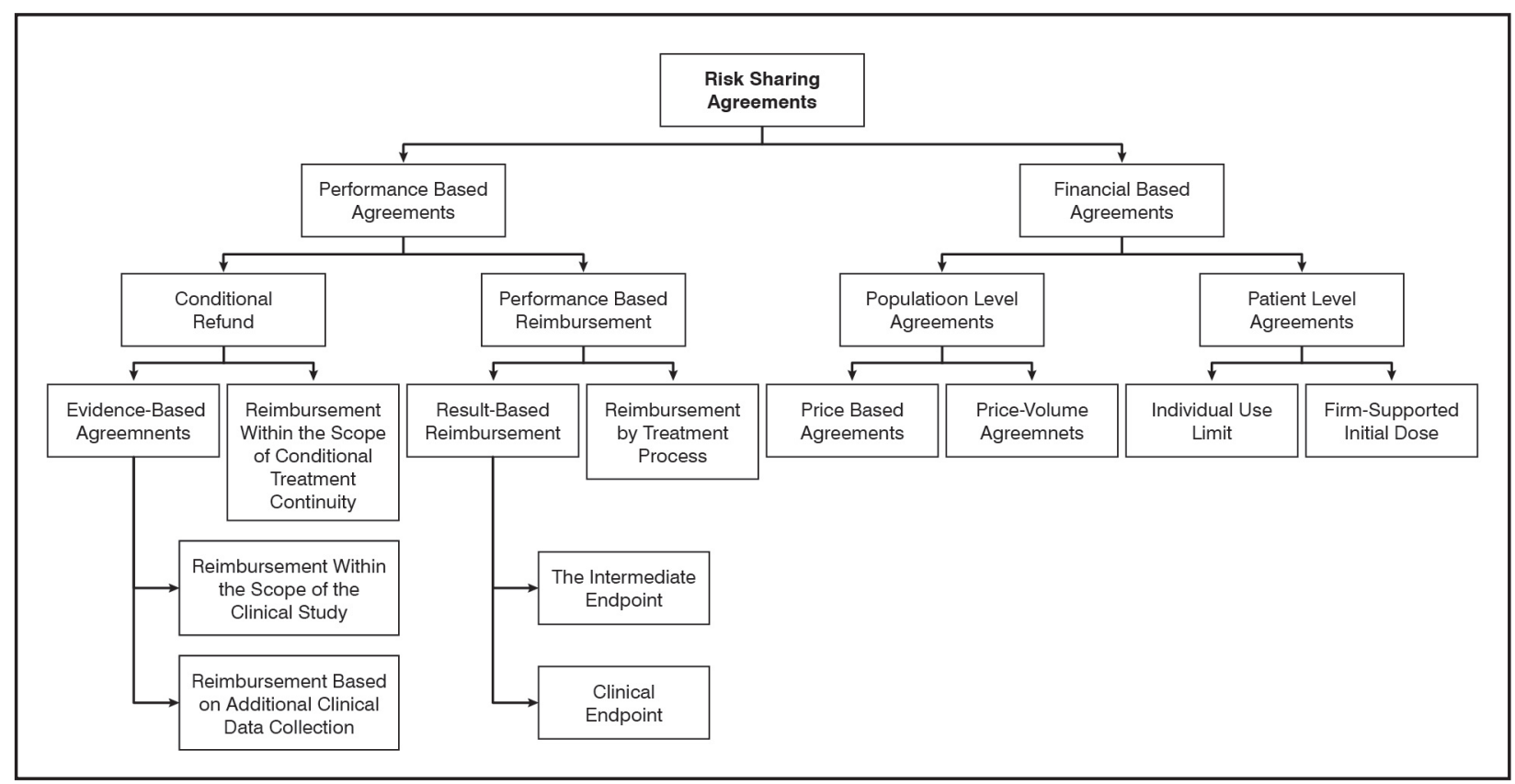

Figure 1. Risk Sharing Agreements. Modified from [23] 
Research has demonstrated that more than half of an individual's health expenditure is spent after retirement. Therefore, it can be said that market access will become a crucial issue in coming years [20].

Turkey will soon become the fastest-aging country in the OECD by 2050 [21]. Such a development provides a challenge for the public and an opportunity for pharmaceutical companies [20].

Market access agreements may occur in a variety of ways, such as price-volume agreements, outcome-guaranteed programs, and proof-of-evidence payment. These agreements can be defined as "risk-sharing agreements," "performance-based agreements," "patient access programs," and "managed input agreements" [22].

Risk-sharing agreements can be divided into two main classes: finance-based models and outcome- or performance-based models [23] (Figure 1). The model to be applied should be decided according to the need of the payer and the suitability of the country's infrastructure. In general, performance-based models are used in conditions of clinical uncertainty, and financebased models are used in conditions that involve uncertainties about the budget [24].

Depending on the type of agreement, pharmaceutical companies either offer discounts on sales volume (price-volume agreements) or apply total or partial reimbursements when treatments are not as effective and safe as initially believed (payment agreements for performance) [25].

\section{Performance-Based Agreements}

Performance-based agreements are defined as agreements between the healthcare provider and medical product manufacturers in which price, level, or quality of reimbursement depends on future clinical or intermediate termination point measurements of the patient's quality of life or life decency. It is based on predefined outputs or new evidence, usually clinical [26]. Such agreements regulate the reimbursement of the product on designated patients within a given period, according to their established health outcomes [27]. In these models, an agreement is reached between the company and the payer to conduct a program on evidence or data collection. The program is initiated or requested by the payer. The objective is to reduce the uncertainties associated with the long-term efficacy and the cost-effectiveness of the drug [24].

\section{Conditional refund}

Conditional refund is the preferred model for medicinal products that are new but not available for reimbursement due to the lack of existing data or real-life data. Such agreements create opportunities for real-life data for both reimbursement institutions and pharmaceutical companies while ensuring that companies do not lose time in market access [27]. These agreements include the reimbursement of a portion of the cost spent by the manufacturer if the drug does not achieve the desired result in the appropriate population [28]. Conditional reimbursement models are divided into two subclasses: evidence-based reimbursement and conditional treatment continuity.

Evidence-based reimbursement includes reimbursement of treatment or technology that requires data collection through clinical research or registration with the participation of the manufacturer to determine the effectiveness of specific promising technologies [29]. It is divided in reimbursement within the scope of the clinical study, which refers to reimburse depending on the provided clinical data from the manufacturer supported clinical trials [27], and reimbursement based on additional clinical data collection, in which, in case of insufficient clinical data, the reimbursement institution includes the product in the scope of reimbursement provided that the manufacturer collects additional clinical data [28].

Reimbursement within the Scope of Conditional Treatment Continuity is reimbursement for ongoing treatment in patients who have achieved the targeted clinical effect. Furthermore, such programs may include full or partial reimbursements for patients who did not achieve the targeted effect [27]. It is a model in which the payer provides temporary funding to collect the information necessary to reduce existing uncertainties regarding a coverage decision. The disadvantage of these agreements is that the drug does not provide the benefit of the clinical trial in real life due to errors in patient selection [30].

\section{Performance-based reimbursement}

Performance-based reimbursement is based only on real-life clinical results. The pharmaceutical company agrees to provide a certain number of products free of charge based on data from clinical trials. For patients who benefit at the end of the process, the drug is included in reimbursement. For patients with no benefit, different treatment options are investigated [27]. Performance-based reimbursement is divided into two categories: result guaranteed reimbursement and reimbursement by treatment process. 
In the result-based reimbursement pharmaceutical company takes a refund or a discount to the paying institution for the patient group when a reimbursed drug does not provide any benefit. It is a model where the price is directly linked to a specific outcome for each patient. Regarding the agreement in the treatment process, according to the evaluations made at the intermediate endpoint or clinical endpoint, a certain portion of the costs of the patients who do not respond to treatment are paid by the company to the paying institution [28]. The reimbursement by treatment process occurs when the company selects patients using biological markers, such as genetic testing, under clinical treatment guidelines [27].

\section{Financial Based Agreements}

These types of agreements are used to manage financial risks due to uncertainty in estimating general use or cost or to reduce payment risk from using drugs off the restricted list [31]. Financial contracts are usually discount-based and have a direct impact on the net price. Since the aim is not to prove the effectiveness of the drug but to eliminate financial uncertainty, there is no need to collect patient data [32].

\section{Patient-Level Agreements}

Patient-level agreements model is defined as setting different prices for a particular technology in different patients. However, the price level is not only determined by the patient outcomes but is also linked to other treatment-related factors [28]. It is divided in firm-supported initial dose and individual use limit agreements. Firm-supported initial agreements are used where the cost is borne by the manufacturer, and the total cost for the paying institution is reduced, regardless of success or failure, usually for patients in the initial phase of treatment. The list at the beginning of treatment includes patients receiving technology for a price different from the price [32]. Unlike the conditional treatment continuity model, there is no consensus that treatment will remain within reimbursement if patients achieve a target effect [28]. In the Individual use limit model, also called the individual volume model, the total cost of drugs to be covered by the paying institution per patient is predetermined. If it is determined that the patient requires further treatment after an agreed period of treatment, some or all of the amount exceeded is covered by the manufacturer [28].

\section{Population-level agreements}

Population-level agreements are characterized by effective prices determined at the health-system level instead of at the level of the individual patient [33]. They are divided in price-based and price-volume agreements. Price-based agreements include the discount between the producer and the buyer as a result of bargaining the product per box at the list price. However, examples of such agreements are limited as a result of global reference pricing, where drug pricing in one country is linked to the price in another country [28]. As a result, such agreements are made in the form of confidential discounts and are not published because pharmaceutical companies are afraid of a price war for their products [33]. Confidentiality of the agreements gives the advantage to the reimbursement institution in terms of negotiations for other drugs that are equivalent to the drug and to the company in terms of competition [34]. Price-volume agreements are made against the risk of the product exceeding the estimated number of patients after access to the market is approved and an unexpected increase in drug expenditures. The pharmaceutical company makes a certain price reduction or exceeds the expected payer to the payer when the estimated patient or box sales exceed. In the implementation of this model, it is important to follow the drug meticulously [32].

\section{Market Access in Turkey}

In Turkey, depending on the drug licensing and pricing activity, monitoring and management of the Ministry of Health Turkey Pharmaceuticals and Medical Devices Agency (TPMDA) is implemented through the licensing application by pharmaceutical manufacturers. The "Human Medicinal Products Licensing Regulation" is implemented by TPMDA. The drug reimbursement is made by the Social Security Institution (SSI), which is affiliated to the Ministry of Family, Labor, and Social Services [14,24]. The most important criteria for reimbursement are clinical effectiveness, safety, quality, cost-effectiveness, and affordability [16]. With its reimbursement policies, SSI provides medicines to people under its system and takes measures to ensure that pharmaceutical expenditures do not exceed their budgets. As a result, in 2009 in Turkey, government requested cost-effectiveness and budget impact analysis from the innovative pharmaceutical products. This has required pharmaceutical companies to scientifically prove to the public that their products are cost-effective [20]. 
The difference between income and expense for SSI was determined as 20.656 Million TL in 2016. To cover the budget deficits, the SSI has taken certain measures to reduce health expenditures. In 2014, rational drug use was introduced. For the same purpose, due to the implementation of the global budget between 2010 and 2012, the public drug budget was exceeded, and drug pricing and public discount rates were changed and restrictions were made on drug expenditures [12]. To this end, on February 10, 2016, the Alternative Reimbursement Commission (ARC), the Drug Reimbursement Commission, and the Medical and Economic Reimbursement Commission were published in the official newspaper as subcommissions of the Health Services Pricing Commission (HSPC) [35].

The main purpose of this study was to understand the market access agreements scheme in Turkey.

\section{METHODS}

In this study, with the aim to report the market access agreements in Turkey, relevant legislation, announcements, official publications, and reports were examined. The official sites of the SSI, TPMDA, the official gazette, the Ministry of Health, the Association of Investigative pharmaceutical companies (AIPC), the Pharmaceutical industry employers' union (PIEU), and Turkish Pharmacists' Association (TPA) were used to examine the activities implemented and data included in Turkey since 2016 for the related legislation.

Data were taken from the current TPMDA International Drug List dated January 02, 2019, SSI SUT supplementary lists, Annex-4A List Reimbursement Medicines, and the Annex 4c International Drug Price List. The investigation also included the decisions of HSPC published in the official gazette between October 02, 2016 and January 02, 2019 (Access Date: May 5, 2019).

In the current study, content analysis, a qualitative research method, was used to examine the drugs covered by alternative reimbursement. The alternative reimbursement published in the HSPC decisions, the SSI Health Application Communique (HAC) annex lists, which are included in the list of medicines to be paid in Annex-4A and the Annex-4C International Drug Price List, including the year, price, discount rate, Anatomic Therapeutic Chemical Classification (ATC) code, disease, generic drug, and reimbursement required data were reached for the analysis. The obtained data were transferred to Windows Office Excel files.

\section{RESULTS}

The first market access agreement has been signed for the products used in the treatment of Hepatitis C. The products have received reimbursement approval since June 18, 2016. The public discount rates have not been published for these products, and confidential discounting has been initiated. It was the first time the public discount rates kept confidential in Turkey. Currently, there are 57 drugs included in the alternative reimbursement process (as of May 21, 2019). Ten of these drugs were included in alternative reimbursement in 2016, 13 in 2017, 24 in 2018 , and 10 in 2019.

Of the 57 medicines covered by ARC agreements, 35 were added to the List of Reimbursed Medicines for $4 \mathrm{~A}$ and 22 of them were added to the $4 \mathrm{C}$ international drug price list. Of the drugs listed in $4 \mathrm{~A}$, 32 were original and three were generic products. There were 16 orphan drugs within the scope of ARC. Eight of these drugs were in the list of drugs to be paid for $4 \mathrm{~A}$ price, and 8 were in the $4 \mathrm{C}$ international drug price list. There were no restrictions on reimbursement in 11 of the drugs in the 4A List of Reimbursed Medicines, whereas 24 had restrictions. Eighteen of the products in the $4 \mathrm{C}$ International Drug Price List had restrictions.

L-Antineoplastic and immunomodulatory agents constitute the most common ATC group among the drugs cov-

\begin{tabular}{llccc}
\hline \multicolumn{1}{c}{ ATC Codes } & $\begin{array}{c}\text { Total } \\
\text { (n) }\end{array}$ & $\begin{array}{c}\text { Annex 4A } \\
\text { (n) }\end{array}$ & $\begin{array}{c}\text { Annex 4C } \\
\text { (n) }\end{array}$ \\
\hline L $\quad \begin{array}{l}\text { Antineoplastic and } \\
\text { Immunomodulating Agents }\end{array}$ & 26 & 21 & 5 \\
A $\quad \begin{array}{l}\text { Gastrointestinal Canal } \\
\text { and Metabolism }\end{array}$ & 10 & 3 & 7 \\
J & Systemic Anti-infective & 5 & 5 & - \\
M & Musculoskeletal System & 4 & 1 & 3 \\
N & Nervous system & 3 & 2 & 1 \\
V & Various & 3 & 1 & 2 \\
D & Drugs Used in Dermatology & 2 & 1 & 1 \\
R & Respiratory system & 1 & 1 & - \\
C & Cardiovascular System & 1 & - & 1 \\
B & Blood and Blood Making Organs & 1 & - & 1 \\
N/A & & 1 & - & 1 \\
Total & & $\mathbf{5 7}$ & $\mathbf{3 5}$ & $\mathbf{2 2}$ \\
\hline
\end{tabular}

Table I. Alternative Reimbursement Drugs by ATC 
ered by alternative reimbursement. This group was typically related to cancer and immune system diseases (Table I). Oncology drugs constituted the majority of the drugs that were reimbursed by the ARC. (Table II).

The reimbursement discount rates of $44(77.19 \%)$ products were not published. A confidential discount application was made for these products. Mandatory reimbursement discount of $41 \%$ on $14.03 \%$ of 57 products, other reimbursement discounts of $31 \%$ on $1.75 \%, 29 \%$ on $1.75 \%, 28 \%$ on $1.75 \%, 12 \%$ on $1.75 \%$, and $10 \%$ on $1.75 \%$ were applied. Due to the applied reference price practice in Turkey, products in the other countries may be affected by the reference price changes in Turkey. To protect against this situation, confidential discounts are ap-

\begin{tabular}{|c|c|}
\hline Disease & $\begin{array}{l}\text { Products } \\
\text { (n) }\end{array}$ \\
\hline Malignant Melanoma & 5 \\
\hline Hepatitis C & 4 \\
\hline Breast Cancer & 3 \\
\hline Multiple Sclerosis & 3 \\
\hline Non-Small Cell Lung Cancer & 3 \\
\hline Multiple Myeloma and Plasma Cell Disorders (Rare Disease) & 3 \\
\hline Phenylketonuria (Rare Disease) & 2 \\
\hline MPS (Maroteaux-Lamy) Type VI (Rare Disease) & 1 \\
\hline Chronic Lymphocytic Leukemia & 1 \\
\hline Diabetic Foot Ulcer & 1 \\
\hline Leptin Deficiency (Rare Disease) & 1 \\
\hline Respiratory Inflammation & 1 \\
\hline $\begin{array}{l}\text { Bile Acid Synthesis Disorders and Zellweger Spectrum Disorders } \\
\text { (Rare Disease) }\end{array}$ & 1 \\
\hline Duchenne Muscular Dystrophy (DMD) (Rare Disease) & 1 \\
\hline Osteosarcoma & 1 \\
\hline Ulcerative Colitis and Crohn's Disease & 1 \\
\hline Morquio Syndrome (Rare Disease) & 1 \\
\hline Spinal Muscular Atrophy (SMA) (Rare Disease) & 1 \\
\hline Gaucher's Disease (Rare Disease) & 1 \\
\hline Acute Lymphocytic Leukemia (ALL) & 1 \\
\hline $\begin{array}{l}\text { Paroxysmal Nocturnal Hemoglobinuria and Atypical Hemolytic } \\
\text { Uremic Syndrome (Rare Drug) }\end{array}$ & 1 \\
\hline Parkinson's Disease & 1 \\
\hline Disorders of Urea Cycle Metabolism & 1 \\
\hline Cerebral palsy & 1 \\
\hline Malignant neoplasm & 1 \\
\hline Wilson's Disease & 1 \\
\hline Chronic Hyperuricemia & 1 \\
\hline $\begin{array}{l}\text { Chronic Lymphocytic Leukemia, Mantle Cell Lymphoma (Rare } \\
\text { Disease) }\end{array}$ & 1 \\
\hline Acute and Chronic Leukemia (Rare Disease) & 1 \\
\hline AIDS with Cytomegalovirus (CMV) Retinitis & 1 \\
\hline $\begin{array}{l}\text { Brain Tumors, Multiple Myeloma, Hodgkin's Disease, Non-Hodgkin's } \\
\text { Lymphoma }\end{array}$ & 1 \\
\hline Medullary Thyroid Cancer (Rare Disease) & 1 \\
\hline Eczema & 1 \\
\hline Hunter Syndrome & 1 \\
\hline Leishmaniosis, Free Living Amoeba Infections & 1 \\
\hline Hypertriglyceridemia & 1 \\
\hline $\begin{array}{l}\text { Cancer, Wilson's Disease, Copper Metabolism Disorders: } \\
\text { Seropositive Rheumatoid Arthritis, Rheumatoid Arthritis, other; } \\
\text { Juvenile Arthritis, Amino-acid Transport Disorders }\end{array}$ & 1 \\
\hline Congenital Metabolic and Hereditary Diseases & 1 \\
\hline $\begin{array}{l}\text { MNGIE (Mitochondrial Neurogastrointestinal Encephalomyelopathy), } \\
\text { Congenital Metabolic and Hereditary Diseases }\end{array}$ & 1 \\
\hline $\begin{array}{l}\text { Organic Phosphorus Insecticide and Chemical Composition } \\
\text { Poisoning }\end{array}$ & 1 \\
\hline
\end{tabular}

Table II. Alternative Reimbursement Drugs by disease plied between the company and the paying institution, and the public prices of the products are kept confidential or higher in price lists (Figure 2).

The average reimbursement discount rate of the products whose discount rates were announced was $33.69 \%$. Of the products with published discount rates, a $41 \%$ discount was applied to the list price in 8 of 13 products. All 13 products were added to the Annex-4A List of Reimbursed Medicines and have access to public prices and costs to SSI. The prices of these drugs vary between 9.04 TL (Oxofen $2 \mathrm{mg} / \mathrm{ml} 150 \mathrm{ml}$ with active substance fenspiride hydrochloride) and 16.226,00 TL (Imbruvica $140 \mathrm{mg} 120$ capsules with ibrutinib active substance), but the average public price is 3.839 .67 TL.

When the average of the reference prices of products purchased with an alternative reimbursement method are considered, the overall average was $3.167,00 €$. An examination of the yearly average reveals that the average price was very high in 2016 . This can be explained by the fact that the price of three of the seven products purchased in 2016 was over $€ 8.000 .00$. In 2017, nine products were covered, and the price of five of the products was under $€ 1,000,00$. In 2018, 18 medicines and 29 products were purchased, and 12 of these products cost between 3.000,00 and 8.000,00 €. In 2019, a product (Pralidoxime Methylsulfate - Contrathion) was added to the List of Reimbursed Medicines for $4 \mathrm{~A}$, and the reference price of the product was $€$ 40.50 (Table III).

An examination of the list prices also revealed that the highest general average was for 2017. The reason for this is that the list price of the drug named Spinraza (active ingredient nusinersen) added to the 4C International Drug Price List in 2017 and included in the reimbursement list was $90.000,00 €$.

There was no statistically significant difference between the average list price (Turkish Lira-TL) and the reference price (TL), calculated according to 
the average fixed exchange rate of the drugs included in the List of Reimbursed Medicines in Annex-4A ( $p=0.271)$. There was no significant difference between the average list price $(€)$ of the drugs in the List of Reimbursed Medicines in Annex-4A and the average list price $(€)$ of the drugs in the Annex-4C International Drug Price List $(p=0.169)$. On a year-by-year basis, there was no statistically significant difference between the average list price (TL) of the drugs included in the List of Reimbursed Medicines for Annex-4A in 2016 and the reference price (TL) calculated according to the average fixed rate of 2016 ( $p=0.290)$. Furthermore, no significant difference was detected between the average list price $(€)$ of the drugs included in the List of Reimbursed Medicines in Annex-4A

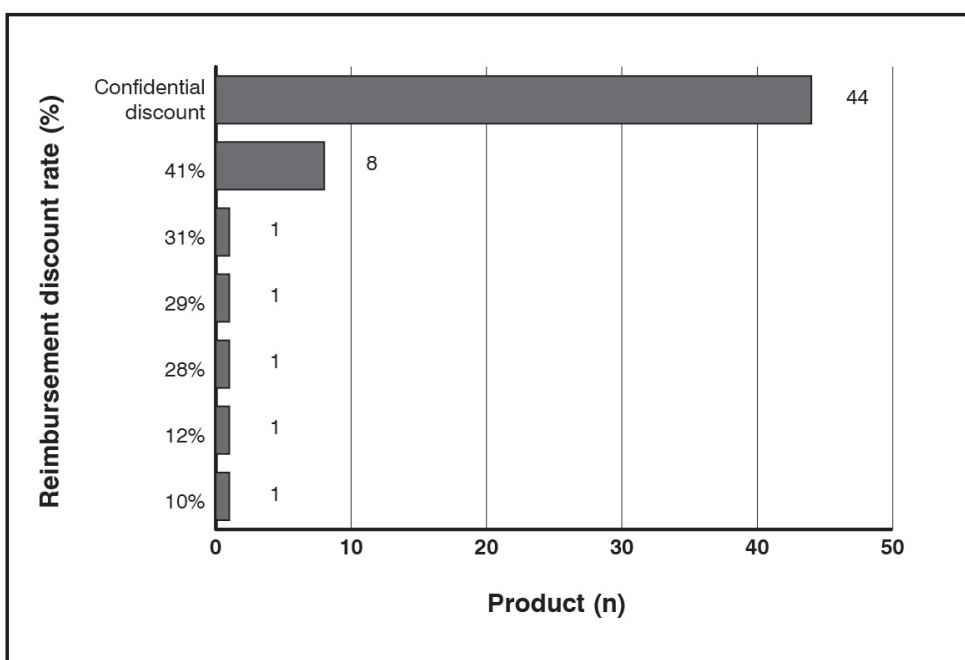

Figure 2. Reimbursement discount rates of drugs covered by alternative reimbursement in 2016 and the average list price $(€)$ of the drugs included in the Annex-4C International Drug Price List in 2016 ( $p=0.320)$. However, a significant difference between the average list price (TL) of drugs included in the List of Reimbursed Medicines for Annex-4A in 2017 and the reference price (TL) calculated according to the 2017 average fixed rate $(p=0.015)$ was detected. Furthermore, a significant difference between the average list price $(€)$ of the drugs included in the List of Reimbursed Medicines in Annex-4A in 2017 and the average list price $(€)$ of the drugs included in the Annex-4C International Drug Price List in 2017 ( $\mathrm{p}=0.177$ ) was found. Results also revealed no significant difference between the average list price (TL) of the drugs included in the List of Reimbursed Medicines in Annex-4A Price (TL) and the reference price (TL) calculated according to the 2018 average fixed exchange rate $(\mathrm{p}=0.169)$. Furthermore, there was no significant difference between the average list price $(€)$ of the drugs included in the List of Reimbursed Medicines in Annex-4A in 2018 and the average list price $(€)$ of the drugs included in the Annex-4C International Drug Price List in 2018 ( $\mathrm{p}=0.222)$.

The most involved pharmaceutical companies in the alternative reimbursement process were Roche, with five drugs, and Abbvie, Biomarin, Gilead, and Takeda with three drugs each. In countries where the prices of the drugs included in the List of Reimbursed Medicines for $4 \mathrm{~A}$ and the alternative reimbursement process are taken as a reference, Switzerland is followed by Greece.

\begin{tabular}{lccccc}
\hline & General & $\mathbf{2 0 1 6}$ & $\mathbf{2 0 1 7}$ & $\mathbf{2 0 1 8}$ & $\mathbf{2 0 1 9}$ \\
\hline Reference Price, Average $\boldsymbol{€}$ (SD) & $3.167,61$ & $5.705,61$ & $1.309,47$ & $3.262,05$ & 40,50 \\
& $(3.262,79)$ & $(5.087,04)$ & $(1.351,09)$ & $(2.807,07)$ & $(-)$ \\
Reference Price Calculated & $10.781,60$ & $19.420,19$ & $4.209,58$ & $11.103,04$ & 137,85 \\
According to Average Fixed & $(11.122,59)$ & $(17.314,77)$ & $(4.806,52)$ & $(9.554,41)$ & $(-)$ \\
Rate, Average TL (SD) & & & & \\
List Price, Average $€$ (SD) & $2.856,58$ & $2.820,79$ & $7.994,18$ & $1.464,45$ & $1.805,92$ \\
& $(10.862,22)$ & $(2.551,48)$ & $(24.677,46)$ & $(1.449,01)$ & $(1.671,80)$ \\
4A List Price, Average $€$ (SD) & $1.572,11$ & $3.017,87$ & 652.37 & 1.560 .74 & 59,07 \\
& $(1.771,29)$ & $(3.014,74)$ & $(749,18)$ & $(1.434,60)$ & $(-)$ \\
4A List Price, Average TL (SD) & $10.480,72$ & $20.119,10$ & $4.349,12$ & $10.404,96$ & 393,77 \\
& $(11.808,61)$ & $(20.098,24)$ & $(4.994,54)$ & $(9.564,02)$ & $(-)$ \\
4C List Price, Average $€$ (SD) & $5.542,28$ & $2.360,94$ & $24.513,25$ & 999,05 & $1.200,01$ \\
& $(18.935,25)$ & $(1.255,43)$ & $(43.690,56)$ & $(1.561,58)$ & $(1.731,42)$ \\
\hline
\end{tabular}

Table III. Average Reference and List Prices of Drugs Covered by Alternative Reimbursement

List prices of the products in the 4A Reimbursed Medicines List issued by the SSI are given in Turkish Lira and the list price of the products in 4C International Drug Price List is given in Euro. To make comparisons, the prices of the products in the rate of 1 Euro $=6,67 \mathrm{TL}$ and $4 \mathrm{C}$ International Drug Price List dated 06.05.2019 are calculated as 1 Euro $=1.11$ Dollars.

Reference Prices include the list of Reimbursed Medicines for $4 \mathrm{~A}$.

The reference prices of the products listed in the 4A Reimbursed Medicines List are given in Euros. The conversion of these products as per the "Pharmaceutical Industry Association of Turkey" published by the "Applied Periodic Euro Value of Drug Price (DAD)" is calculated over. As of 14.02.2019, the fixed exchange rate to be applied for drugs is 3.4037

$\mathrm{SD}=$ standard deviation 


\section{DISCUSSION}

ARC, which was established in line with the regulation issued in 2016, aims to keep pharmaceutical expenditures under control and to deliver the needed treatment to patients at a lower cost with the agreements made between the pharmaceutical companies and the reimbursement institution. In general, alternative reimbursement models are preferred to ensure the reimbursement of high-cost drugs.

In practice, since Turkey launched several drugs that were included in the scope of reimbursement, alternative methods of reimbursement have increased every year. It was found that most of the drugs had been added to the List of Reimbursement Medicines for Annex 4A.

Most of the drugs added to the List of Reimbursement Medicines are regarded as original drugs. This is an indication of the need for reimbursement in new and effective treatments. It could be said that drugs that are added to the list for alternative reimbursement are usually related to oncology and immune system diseases. Due to the high cost of oncology medicine, oncology medicines are mostly included in ARC for controlling the possible budget impact.

Within the scope of alternative reimbursement, approximately $80 \%$ of the drugs added to the List of Reimbursement Medicines for 4A and the List of 4C International Medicines had confidential discounts applied. The purpose of the confidential discount in alternative reimbursement methods is to reach the same public price with higher discounts instead of decreasing the sales price to the warehouse, excluding value added tax (VAT). In this manner, price flexibility is provided, and the market availability of medicines is ensured. Furthermore, the budgetary impact of high-cost drugs on the SSI is reduced by the use of confidential discounts.

\section{CONCLUSIONS}

Market access agreements, named as alternative reimbursement models, in Turkey are beneficial for both reimbursement institutions and pharmaceutical companies. The agreements provide additional discounts for reimbursement institutions and set fixed prices for pharmaceutical companies over the term of the agreement. These study findings are unique in literature and may help decision-makers and companies for their future planning for market access of innovative medicines.

\section{Funding}

This article has been published without the support of sponsors.

\section{Conflicts of interests}

The authors declare they have no competing financial interests concerning the topics of this article.

\section{REFERENCES}

1. Ministry of Health of the Republic of Turkey. Health Transformation Programme 2001. Available at https://sbu.saglik.gov.tr/Ekutuphane/Yayin/133 (last accessed May 2019)

2. Tanios N, Wagner M, Tony M, et al. Which criteria are considered in healthcare decisions? Insights from an international survey of policy and clinical decision-makers. Int J Technol Assess 2013; 29: 456-65; https://doi.org/10.1017/S0266462313000573

3. Maynard A, Bloor K. Dilemmas in the regulation of the market for pharmaceuticals. Health Affair 2003; 22: 31-41; https://doi.org/10.1377/hlthaff.22.3.31

4. Italian Trade Agency. Electro Medicals Market in Turkey. BKP Research\&Consulting, 2016. Available at http://www.farexport.it/wp-content/uploads/2016/03/Elettromedicalein-Turchia.pdf (last accessed May 2019)

5. Commission of the European Communities. Safe, innovative, and accessible medicines: A renewed vision for the pharmaceutical sector. Brussels: Commission of the European Communities. 2008

6. Belloni A, Morgan D, Paris V. Pharmaceutical expenditure and policies: Past trends and future challenges (Report Id: 87). Paris: OECD Publishing, 2016

7. Bang H, Zhao H. Median-Based Incremental Cost-Effectiveness Ratio (ICER). J Stat Theory Pract 2012; 6: 428-42; https://doi.org/10.1080/15598608.2012.695571 
8. Sentürk A. The effect of drug reimbursement policies on drug expenditures in the Social Security System. (Master Dissertation). Retrieved from Ulusal Tez Merkezi. 227923: 50-80

9. Fefer E. Pharmaceutical legislation and regulation. In: Embrey MA, editor. Managing access to medicines and health technologies. Sterling, Virginia: Kumarian Press, 2012. p. 100-120.

10. Embrey MA. Managing access to medicines and health technologies. 3rd ed. Sterling, Virginia: Kumarian Press, 2012

11. Drummond MF, Schwartz JS, Jönsson B, et al. Key principles for the improved conduct of health technology assessments for resource allocation decisions. Int J Technol Assess 2008; 24: 244-58; https://doi.org/10.1017/S0266462308080343

12. Uğurlu M. Evaluation of health technologies and their role in the drug market access process. In: Kahveci R editor. Drug and market access process. Ankara, Türkiye: SAGE Yayıncılık, 2017. p. 59-85

13. Toumi M, Jaroslawski S. Introduction to the Market Access. In. Koçkaya G, Wertheimer A, editors. Pharmaceutical market access in emerging markets. Turin: Seed, 2016. p. 3-20; https://doi.org/10.7175/747.ch1

14. Koçkaya G, Kılıç P. Pharmaceutical policies and market access. ISPOR Connections. $2012 ; 1-3$

15. Kahveci R. Drug and market access process. 1st ed. Ankara: SAGE Yayıncılık, 2017

16. Koçkaya G. Introduction to market access. 2018. Available at http://sepd.org.tr/wp-content/ uploads $/ 2018 / 01 / \mathrm{G} \% \mathrm{C} 3 \% \mathrm{BCven} \% \mathrm{C} 3 \% \mathrm{~A} 7-\mathrm{Ko} \% \mathrm{C} 3 \% \mathrm{~A} 7 \mathrm{kaya}-\mathrm{Pazar}-\mathrm{Eri} \% \mathrm{C} 5 \% 9 \mathrm{Fime}-$ Giri\%C5\%9F-v2.ppt (last accessed May 2019)

17. Cook JP, Vernon JA, Manning R. Pharmaceutical risk-sharing agreements. Pharmacoeconomics 2008; 26: 551-6; https://doi.org/10.2165/00019053-200826070-00002

18. Carone G, Schwierz C, Xavier A. Cost-containment policies in public pharmaceutical spending in the EU (Rapor No:461). Brussels: European Commission, 2012; https://doi. org/10.2139/ssrn.2161803

19. Kharvi S, Pakkala TPM, Srinivasan G. Ordering policies under currency risk-sharing agreements: A Markov chain approach. Opsearch 2019; 1-20; https://doi.org/10.1007/ s12597-019-00394-Z

20. Koçkaya G. Value-based pricing within drug pricing methods. In: Kahveci R, editor. Drug and market access process. Ankara, Türkiye: SAGE Yayınc1lı, 2017. p. 126-133.

21. OECD. Pensions at a Glance 2017: OECD and G20 Indicators. Paris: OECD Publishing, 2017. p. $122-3$

22. Ferrario A, Kanavos P. Managed entry agreements for pharmaceuticals: The European experience. LSE. 2013. Available at http://eprints.lse.ac.uk/50513/ (last accessed May 2019)

23. Carlson JJ, Sullivan SD, Garrison LP, et al. Linking payment to health outcomes: A taxonomy and examination of performance-based reimbursement schemes between healthcare payers and manufacturers. Health Policy 2010; 96: 179-90; https://doi.org/10.1016/j. healthpol.2010.02.005

24. Dinç M. Overview of pharmaceutical reimbursement system in Turkey and evaluation of transition process to alternative reimbursement models. (Master Dissestation). Retrieved from Ulusal Tez Merkezi. 489688: 16-43

25. Lorente R, Antonanzas F, Rodriguez-Ibeas R. Implementation of risk-sharing contracts as perceived by Spanish hospital pharmacists. Health Economics Review 2019; 9: 25; https:// doi.org/10.1186/s13561-019-0242-x

26. Garrison Jr LP, Towse A, Briggs A, et al. Performance-based risk-sharing arrangements-good practices for design, implemention, and evaluation: Report of the ISPOR good practices for performance-based risk-sharing arrangements task force. Value Health 2013; 16: 703-19; https://doi.org/10.1016/j.jval.2013.04.011

27. Beykoz V. Performance-based models. In: Kahveci R, editor. Drug and market access process. Ankara, Türkiye: SAGE Yayıncılık, 2017. p. 141-7 
28. Walker S, Sculpher M, Claxton K, et al. Coverage with evidence development, only in research, risk sharing or patient access scheme? A framework for coverage decisions. CHE Research Paper 77. Center for Health Economics. 2012; https://doi.org/10.1016/j. jval.2011.12.013

29. Walker S, Sculpher M, Claxton K, et al. Coverage with evidence development, only in research, risk sharing or patient access scheme? A framework for coverage decisions. CHE Research Paper 77. University of York: Centre for Health Economics, 2012. Available at https://www.york.ac.uk/media/che/documents/papers/researchpapers/CHERP77_a_framework_for_coverage_decisions_only_in_research_evidence_development.pdf (last accessed May 2019)

30. Medicare's Coverage With Evidence Development: A Policy-Making Tool in Evolution. $J$ Oncol Pract 2007; 3: 296-301; https://doi.org/10.1200/JOP.0763501

31. Espin J, Rovira J, Garcia L. Experiences and impact of European risk-sharing schemes focusing on oncology medicines. Brussels: Commissioned by the European Commission, Directorate-General Enterprise, 2011

32. Vitry A, Roughead E. Managed entry agreements for pharmaceutical in Australia. Health Policy 2014; 117: 345-52; https://doi.org/10.1016/j.healthpol.2014.05.005

33. Dokuyucu Ö. Financial-based models. In: Kahveci R, editor. Drug and market access process, Ankara, Türkiye: SAGE Yayıncılık, 2017. p. 148-52

34. Vogler S, Zimmermann N, Habl C, et al. Discounts and rebates granted to public payers for medicines in European countries. Southern Med Review 2012; 5: 38-46; https://doi. org/10.2174/1876824520130426001

35. Demir C. Evaluation of the views and preferences of stakeholders on the drug policies implemented in Turkey by using the Multi-Criteria Decision Making Method (ELECTRE III). (Master Dissestation). Retrieved from Ulusal Tez Merkezi. 509928:65-82

36. Official Gazette. Social Security Institution General Health Insurance Alternative Reimbursement Regulation. 2016. Number: 29620. Available at http:/www.resmigazete.gov.tr/ eskiler/2016/02/20160210-6.htm (last accessed Apr 2019) 